\title{
A hiponatremia como fator preditivo da perda precoce do transplante hepático na modalidade intervivos
}

\author{
Hyponatremia as a predictor factor of early loss after living donor liver \\ transplantation
}

Sofia Abdalla', Rogério Camargo Pinheiro Alves² ${ }^{2}$ Eduardo Antunes da Fonseca ${ }^{3}$, Rodrigo Vicenzi ${ }^{3}$, José Eduardo Gonçalves² ${ }^{2}$ Jaques Waisberg $^{4}$

\section{RESUMO}

Introdução: O transplante hepático intervivos representa alternativa para reduzir a falta de doação de órgãos. Objetivo: Analisar a influência da natremia como fator preditivo da perda precoce do transplante hepático nos três primeiros meses na modalidade intervivos. Método: Estudo retrospectivo, observacional e analítico de 78 doentes adultos submetidos ao transplante de fígado com doador vivo. A média etária foi $50,7 \pm 6,8$ anos (18 a 65 anos) e dividiu-se os doentes transplantados em grupo I, com $62(79,5 \%)$ pacientes com sobrevivência do enxerto superior a três meses, e grupo II com $16(20,5 \%)$, que faleceram e/ou apresentaram falha do enxerto no prazo de até três meses após a realização do transplante hepático. Foram analisadas as seguintes variáveis: sexo, idade, etiologia da doença hepática e o nível sérico de sódio no momento do transplante. Foi considerada "perda precoce" a sobrevivência do enxerto hepático menor que três meses após a realização do transplante. Na avaliação dos fatores de risco para perda precoce do enxerto hepático foram utilizados o teste do $\chi^{2}$, o teste $t$ de Student e a análise uni e multivariada. A análise de sobrevivência do enxerto foi realizada pelo modelo de Kaplan-Meier. Resultados: Sexo $(p=0,4)$ e idade $(p=0,67)$ não apresentaram diferença significante. $O$ nível sérico de sódio foi significantemente $(p=0,01)$ maior no grupo I do que no grupo II. Conclusão: Os valores da natremia estão associados à maior probabilidade de sucesso no transplante hepático na modalidade intervivos.

Palavras-chave: transplante; transplante de fígado; prognóstico; disfunção primária do enxerto; sobrevivência de enxerto; doadores vivos.

\begin{abstract}
Introduction: Living donor liver transplantation has become an appreciable and effective alternative to reduce the problem resulting from the lack of organ donation. Objective: To analyze the influence of serum sodium as a predictor of early loss of liver transplantation in the first three months in living donor modality. Method: In this analytical study, 78 adults submitted to living donor liver transplantation were studied retrospectively. The mean age was $50.7 \pm 6.8$ years (18 to 65 years). The transplant recipients were divided into two groups: group I consisted of $62(79.5 \%)$ patients with graft survival longer than three months, and group II consisted of $16(20.5 \%)$ patients who died and/or showed graft failure within three months after liver transplantation. The following variables were analyzed: gender, age, etiology of liver disease and serum sodium concentration at the time of transplantation. Liver graft survival of less than three months after transplantation was defined as "early loss". The $\chi^{2}$ test, Student's $t$-test and uni and multivariate analysis were used for the evaluation of risk factors for early graft loss. Graft survival was analyzed using the Kaplan-Meier model. Results: No significant difference in gender $(p=0.4)$ and age $(p=0.67)$ was observed between the two groups. Serum sodium concentration was significantly $(p=0.01)$ higher in group I than in group II. Conclusion: Serum sodium concentration is associated with a higher probability of graft failure after living donor liver transplantation.
\end{abstract}

Keywords: transplantation; liver transplantation; prognosis; primary graft dysfunction; graft survival; living donors. 


\section{INTRODUÇÃO}

O transplante é procedimento capaz de salvar vidas de pessoas com doenças crônicas do fígado em estágio final ou com insuficiência hepática aguda (ALF) ${ }^{1-3}$. Thomas Starzl, em 1963, realizou os três primeiros transplantes de fígado sem, no entanto, os doentes atingirem sobrevivência de um ano ${ }^{4}$.

Desde o início da década de 1980, houve avanços significantes em todos os aspectos do transplante hepático ${ }^{3,4}$. Em 1983, a melhora dos resultados clínicos do transplante hepático motivou o National Health Institute (EUA) a reconhecer que o transplante de fígado já não era mais procedimento experimental e merecia ampla aplicação na prática clínica ${ }^{4}$.

Geralmente a sobrevivência de um ano pós-transplante hepático com doador cadavérico em pacientes adultos ou pediátricos é superior a $85 \%$, e a sobrevivência de cinco e dez anos superior a 70 e $60 \%$, respectivamente $e^{5-10}$. Em consequência, o sucesso do transplante hepático como tratamento para a maioria dos tipos de insuficiência hepática aguda e crônica aumentou o número de doentes referenciados para transplante sem a proporcional captação e disponibilização de órgãos ${ }^{1,11}$.

A constante falta de doadores de órgãos é considerada responsável pela carência no atendimento à crescente demanda para o transplante do fígado ${ }^{1,2}$. Esse tipo de desequilíbrio entre a oferta de órgãos e de pacientes aguardando o procedimento é elevado e preocupante, especialmente nas regiões do Leste da Ásia, incluindo Coreia do Sul, Japão, Hong Kong e Taiwan, por questões culturais ${ }^{12}$. Não menos grave é a situação observada no Brasil ${ }^{9,10}$.

O transplante hepático na modalidade intervivos tem sido opção importante para aqueles que aguardam na lista de espera, e a seleção adequada dos receptores é fundamental para evitarmos retransplantes e complicações inerentes ao procedimento, inclusive a morte do receptor por disfunção do enxerto hepático ${ }^{12-14}$.

Neste contexto, o procedimento intervivos passou a ser alternativa eficaz para amenizar o problema representado pela falta de doação de órgãos ${ }^{5,9,10,13}$. Para a contínua melhora dos resultados é importante buscar-se estabelecer critérios capazes de predizer o seu sucesso, visto que o transplante intervivos é operação altamente complexa e envolve outro ser humano saudável (doador), que só deve ser submetido à doação caso as oportunidades de sucesso sejam expressivas ${ }^{10-14}$.

O sucesso do transplante hepático intervivos na população pediátrica levou ao aprimoramento desta técnica para a população adulta $^{11}$. Entretanto, fatores que influenciariam a sobrevivência dos enxertos não foram suficientemente investigados.

No Brasil, durante o primeiro trimestre de 2012, houve 410 transplantes hepáticos, dos quais 23 (5,6\%) foram na modalidade intervivos, todos realizados em São Paulo (19 casos) e no Rio de Janeiro (quatro) ${ }^{15}$.

A atual política de alocação de órgãos em transplante de fígado é dar prioridade aos doentes mais graves, principalmente usando o modelo para a fase final da doença de fígado (MELD) para a devida pontuação ${ }^{16-19}$. No entanto, outros fatores, como o sódio sérico, podem ser de valor na predição de mortalidade precoce $\mathrm{e}^{20-22}$.

A hiponatremia constitui importante marcador de prognóstico sombrio nos doentes que aguardam pelo transplante, além de estar associada ao aumento da mortalidade em pessoas com cirrose avançada e hipertensão portal ${ }^{23,24}$. O objetivo deste estudo foi analisar a influência da natremia como fator preditivo da perda precoce do enxerto hepático nos três primeiros meses após o transplante na modalidade intervivos.

\section{MÉTODO}

Esse estudo foi realizado de acordo com os padrões éticos aceitos pela Declaração de Helsinki da Associação Médica Mundial, adotado em 1964 e emendado em 1996. O projeto de pesquisa foi aprovado pelo Comitê de Ética em Pesquisa (CEP) do Instituto de Assistência Médica ao Servidor Público Estadual (IAMSPE) de São Paulo (parecer nº 026/10).

A pesquisa é observacional, retrospectiva e analítica e nela foram incluídos 78 doentes adultos consecutivos de ambos os sexos submetidos ao transplante de fígado com doador vivo no Programa de Transplantes do Hospital A.C. Camargo (São Paulo, SP, Brasil) e do Hospital Sírio-Libanês (São Paulo, SP, Brasil), no período de junho de 1999 a fevereiro de 2008, pela mesma equipe cirúrgica e em condições de infraestrutura semelhante nos dois locais. Quarenta e nove $(62,8 \%)$ dos doentes transplantados eram do sexo feminino e 29 (37,2\%) do masculino. A média de idade foi $50,7 \pm 6,8$ anos (18 a 65 ).

Os critérios de inclusão foram: idade adulta (acima de 18 anos) e presença prévia de descompensações da doença hepática (hemorragia digestiva alta, ascite e encefalopatia hepática) ou de carcinoma hepatocelular, de acordo com os critérios de Milão (um nódulo com até $5 \mathrm{~cm}$ no maior eixo ou três nódulos com até $3 \mathrm{~cm}$ no maior eixo).

Os critérios de exclusão foram idade inferior a 18 anos, presença de doenças cardiopulmonares descompensadas e/ou graves, neoplasias de qualquer localização e síndrome da imunodeficiência adquirida (AIDS).

Dos 78 doentes estudados, 76 (97,4\%) apresentavam cirrose hepática e dois $(2,6 \%)$ eram portadores de poliamiloidose familiar hereditária. Dentre os doentes cirróticos, a etiologia mais frequente associada à doença hepática foi a hepatite $\mathrm{C}$ em 34 (43,64\%) dos enfermos, hepatite alcoólica em 20 (25,7\%) e hepatite tipo B em dez (12,8\%). Doze (15,3\%) pacientes apresentavam outras causas de cirrose. Todos os transplantes foram realizados com doadores com idade entre 18 e 50 anos e compatibilidade do sistema sanguíneo ABO entre o doador e o receptor.

O doador considerado apto à doação apresentou avaliação clínica-laboratorial (hemograma, bioquímica, sorologias virais, marcadores tumorais, radiografia de tórax, eletrocardiograma, 
ultrassonografia de abdômen total e ressonância nuclear magnética de abdômen) dentro dos parâmetros da normalidade.

Todos os doadores registravam índice de massa corporal (IMC) com valores entre 18 e 25 e ausência de doenças crônicas de qualquer natureza. No caso em que não apresentavam parentesco com os receptores, houve necessidade de autorização judicial.

Os doentes transplantados foram divididos em dois grupos. O grupo I foi composto por $62(79,5 \%)$ pessoas com sobrevivência do enxerto superior a três meses. E o II constitui-se por $16(20,5 \%)$ pacientes que faleceram e/ou apresentaram falha do enxerto no prazo de até três meses após a realização do transplante hepático.

Em relação aos doentes receptores do transplante hepático foram analisadas as seguintes variáveis no período pré-transplante: sexo, idade, etiologia da doença hepática e nível sérico de sódio no momento do transplante. Os valores normais do sódio sérico considerados foram entre $135 \mathrm{mEq} / \mathrm{L}$ e $150 \mathrm{mEq} / \mathrm{L}$.

Foi considerada "perda precoce" a sobrevivência do enxerto hepático menor que três meses após a realização do transplante. E na avaliação dos fatores de risco para perda precoce do enxerto hepático foram utilizados, para as variáveis categóricas, o teste do $\chi^{2}$ e, para as numéricas, o teste $t$ de Student. Realizou-se também a análise univariada dos fatores considerados de risco para a perda precoce do enxerto hepático, incluindo sexo, idade e sódio sérico.

Os programas estatísticos utilizados foram Microsoft Excel 2007 e SPSS 16.0 para Windows 2007 (SPSS Inc., EUA).

\section{RESULTADOS}

Verificou-se que o sexo $(p=0,40)$ e a idade $(p=0,67)$ dos doentes de ambos os grupos não apresentaram diferença significante (Tabela 1). O nível sérico de sódio foi significantemente $(\mathrm{p}=0,01)$ maior no grupo I do que no grupo II. Quando utilizado o corte (cut-off) de valores inferiores a $135 \mathrm{mEq} / \mathrm{mL}$ do nível sérico de sódio, constatou-se que o número de doentes do grupo I com valores de natremia superiores a $135 \mathrm{mEq} / \mathrm{mL}$ foi significantemente maior $(p=0,03)$ do que no grupo II.

Tabela 1: Sexo, idade e níveis séricos de sódio dos doentes submetidos ao transplante hepático intervivo com sobrevivência do enxerto superior a três meses (grupo I) ou que apresentaram falha do enxerto no prazo de até três meses após a realização do transplante (grupo II)

\begin{tabular}{|c|c|c|c|c|}
\hline & & $\begin{array}{c}\text { Grupo I }(n=62) \\
n(\%)\end{array}$ & $\begin{array}{c}\text { Grupo II }(n=16) \\
n(\%)\end{array}$ & Valor $p$ \\
\hline \multirow{2}{*}{ Sexo } & Feminino & $37(59,7)$ & $12(75)$ & \multirow{2}{*}{0,40} \\
\hline & Masculino & $25(40,3)$ & $4(25)$ & \\
\hline \multicolumn{2}{|c|}{ Idade (anos) } & $51,66 \pm 11,90$ & $49,81 \pm 12,71$ & 0,67 \\
\hline \multicolumn{2}{|c|}{$\mathrm{Na}^{+}$sérico } & $138,95 \pm 3,9$ & $134,56 \pm 6,4$ & $0,01^{*}$ \\
\hline
\end{tabular}

\section{DISCUSSÃO}

O transplante de fígado na modalidade intervivos tem sido opção importante para aqueles que aguardam pelo procedimento na lista de espera, e a seleção adequada dos receptores é fundamental para evitarmos retransplantes e complicações inerentes a ele, inclusive a morte do receptor por disfunção do enxerto hepático ${ }^{12-14}$

O presente estudo abordou doentes submetidos ao transplante com doador vivo e seus resultados foram semelhantes aos de outras séries ocidentais com doador vivo ou faleci$\mathrm{do}^{5,11,12,16-18}$. Nesta série, a etiologia mais frequente da doença hepática, que levou o doente ao transplante, foi a hepatite $\mathrm{C} \mathrm{e}$ houve predomínio do sexo masculino, o que também foi observado por outros autores ${ }^{5,6}$.

Poucos estudos na literatura analisaram os fatores que contribuem para a perda do enxerto hepático nos três primeiros meses após o transplante, sobretudo quando consideramos a doação hepática intervivos ${ }^{14}$. Outros autores estudaram os fatores associados ao retransplante hepático, tais como a trombose da artéria hepática ${ }^{19}$, disfunção global do enxerto (primer nonfunction) ${ }^{19}$, síndrome do enxerto pequeno (small for size syndrome) ${ }^{16}$ e rejeição celular hiperaguda ${ }^{16}$.

Para a contínua melhora dos resultados, é importante buscar-se estabelecer critérios capazes de predizer o sucesso do procedimento, visto que o transplante intervivos é operação altamente complexa e envolve outro ser humano saudável (doador), que só deve ser submetido à doação caso as oportunidades de sucesso sejam expressivas $^{13,16}$. O aumento da sobrevivência e a melhora dos resultados com doadores vivos foram obtidos quando foram usados critérios rigorosos de seleção para doadores e receptores ${ }^{16,18,21}$.

Gruttadauria et al. ${ }^{14}$ mostraram que o valor do nível sérico de sódio associou-se significantemente com a disfunção precoce do enxerto, ou seja, quanto menor o valor do sódio sérico, maior a probabilidade do doente perder o enxerto precocemente.

Londoño et al. ${ }^{22}$ demonstraram que no intervalo de valores de sódio sérico entre 120 e $135 \mathrm{mEq} / \mathrm{L}$, cada decréscimo de $1 \mathrm{mEq} / \mathrm{L}$ representa aumento do risco de mortalidade de $12 \%$ no período de três meses após o transplante hepático. Este mesmo estudo apresentou que doentes sem hiponatremia grave, mas com valores de sódio sérico próximos aos limites inferiores da normalidade (130 a $135 \mathrm{mEq} / \mathrm{L})$, tiveram sobrevivência significantemente maior do que aqueles com hiponatremia grave, porém menor em relação aos doentes com valores normais de sódio sérico.

As explicações para a relação entre os níveis baixos de sódio e o aumento da perda precoce do enxerto ainda não estão completamente esclarecidas ${ }^{22-24}$. No entanto, notou-se que o nível de sódio sérico reflete a severidade da disfunção renal e falência circulatória nos hepatopatas. Daí a alta associação da hiponatremia com ascite, encefalopatia hepática, sangramentos do trato gastrointestinal, peritonite bacteriana espontânea e falência renal ${ }^{22-24}$.

Estudos $^{21-23}$ mostraram que a natremia é importante fator prognóstico de sobrevivência de três e 12 meses do transplante 
intervivo em doentes na lista de espera para o transplante hepático. Consequentemente, quanto menor a natremia, maior será a mortalidade dos doentes que aguardam o transplante do órgão.

A hiponatremia constitui importante marcador de prognóstico sombrio nas pessoas que aguardam pelo procedimento, além de estar associada ao aumento da mortalidade em doentes com cirrose avançada e hipertensão portal ${ }^{23,24}$.

Dawwas et al. ${ }^{24}$ correlacionaram a presença de hiponatremia com a mortalidade após transplante cadavérico. O valor do sódio sérico nesta série se relacionou com o índice de sobrevivência menor entre os doentes transplantados.

No presente estudo verificou-se que o sódio sérico menor que $134 \mathrm{mEq} / \mathrm{L}$ no período pré-transplante estava associado à perda precoce do enxerto bem como o impacto maior dos valores baixos de sódio sobre a sobrevida nos três primeiros meses após o transplante. Pesquisas propuseram a inclusão do valor de sódio sérico nos critérios da classificação mais utilizada atualmente para a estratificação de risco de pessoas com doença hepática em estágio terminal ${ }^{25}$. Esta classificação, denominada Model for End Stage Liver Disease (MELD) inclui como critérios de estratificação os valores da bilirrubina sérica, creatinina sérica, International Normalized Ratio (INR) e tempo de protrombina ${ }^{25-26}$.

Ruf et al. ${ }^{27}$ observaram que a presença de hiponatremia isoladamente não demonstrou acurácia significante para predição da mortalidade nesses doentes. Porém, adicionada aos critérios do MELD, o achado de hiponatremia elevou consideravelmente sua acurácia para estimar a perda precoce do enxerto e a mortalidade dos doentes com transplante hepático.

Sirivatanauksorn et al. $^{28}$ analisaram, retrospectivamente, 97 doentes pós-transplante de fígado. A maioria das indicações foi por hepatite B ou C, cirrose alcoólica e carcinoma hepatocelular. A incidência de disfunção primária do transplante foi de 31,9\% (31/97) e o nível mais baixo de sódio sérico foi considerado fator de risco potencial.

Moini et al. ${ }^{29}$ descreveram doentes adultos com cirrose aguardando transplante de fígado acompanhados por seis meses, a partir do momento da listagem, para avaliar o valor da hiponatremia sobre a mortalidade. Dos 612, 51 foram transplantados e 55 morreram sem o procedimento dentro dos primeiros três meses. Os números de transplantados e que faleceram durante o terceiro e o sexto mês pós-transplante foram 29 e 24, respectivamente. Tanto o escore MELD quanto o nível de sódio sérico no momento da listagem foram preditores independentes de mortalidade precoce. Em análise multivariada, o sódio sérico $<130 \mathrm{mEq} / \mathrm{L}$ foi preditor significante de mortalidade em 90 e 180 dias.

Cywinski et al..$^{30,31}$ notaram que a hipernatremia do doador e a hiponatremia do receptor apresentaram impacto negativo sobre a função do enxerto após o transplante hepático.

Selcuk et al. ${ }^{32}$ investigaram possíveis fatores preditivos independentes, além do escore MELD, para a sobrevivência de doentes com cirrose. Os autores analisaram o nível sérico de sódio em 99 doentes com cirrose e investigaram a possível correlação deste parâmetro com a sobrevivência. Observaram que a sobrevivência de seis meses em doentes com níveis séricos de sódio $<125 \mathrm{mM}$ no momento da admissão ao estudo foi $27 \%$ menor do que em doentes com níveis de sódio $>130$ mM. Pessoas com cirrose e níveis séricos de sódio >130 $\mathrm{mM}$ sobreviveram por mais de um ano (IC95\%). O MELD dos doentes com níveis séricos de sódio $>130$, entre 125 e 129 , e $<125 \mathrm{mM}$ foram 15,8-19,9, 19,7-23,6 e 23,3-27,2, respectivamente (IC95\%). Os autores sugeriram que, apesar de todos estes parâmetros estarem correlacionados com a sobrevivência de doentes com cirrose, o nível sérico de sódio é o fator prognóstico mais preciso e instrumento considerado válido para predizer a sobrevivência.

Os resultados obtidos no presente estudo sugerem que no doente submetido ao transplante hepático com doador vivo o nível do sódio sérico constitui fator preditivo da perda precoce do enxerto hepático nos três primeiros meses após o transplante hepático na modalidade intervivos. Entretanto, são necessários estudos adicionais para confirmarem os resultados obtidos na presente série.

\section{REFERÊNCIAS}

1. Ahmed A, Keeffe EB. Current indications and contraindications for liver transplantation. Clin Liver Dis. 2007;11(2):227-47.

2. Murray KF, Carithers RL Jr, AASLD. AASLD practice guidelines: evaluation of the patient for liver transplantation. Hepatology. 2005;41(6):1407-32.

3. Yoshida R, Iwamoto T, Yagi T, Sato D, Umeda Y, Mizuno K, et al. Preoperative assessment of the risk factors that help to predict the prognosis after living donor liver transplantation. World J Surg. 2008;32(11):2419-24

4. Northup PG, Abecassis MM, Englesbe MJ, Emond JC, Lee VD, Stukenborg GJ, et al. Addition of adult-to-adult living donation to liver transplant programs improves survival but at an increased cost. Liver Transpl. 2009;15(2):148-62.

5. Jain A, Reyes J, Kashyap R, Dodson SF, Demetris AJ, Ruppert K, et al. Long-term survival after liver transplantation in 4,000 consecutive patients at a single center. Ann Surg. 2000;232(4):490-500.

6. Gordon RD, Fung J, Tzakis AG, Todo S, Stieber A, Bronsther O, et al. Liver transplantation at the University of Pittsburgh, 1984 to 1990. Clin Transpl. 1991:105-17.

7. Abbasoglu O, Levy MF, Brkic BB, Testa G, Jeyarajah DR, Goldstein RM, et al. Ten years of liver transplantation: an evolving understanding of late graft loss. Transplantation. 1997;64(12):1801-7. 
8. Asfar S, Metrakos P, Fryer J, Verran D, Ghent C, Grant D, et al. An analysis of late deaths after liver transplantation. Transplantation. 1996;61(9):1377-81.

9. Coelho JC, de Freitas AC, Matias JE, de Godoy JL, Zeni Neto C, Parolin MB, et al. Donor complications including the report of one death in right-lobe living-donor liver transplantation. Dig Surg. 2007;24(3):191-6.

10. Coelho JCU, Parolin MB, Baretta GAP, Pimentel SK, Freitas ACT, Colman D. Qualidade de vida do doador após transplante hepático intervivos. Arq Gastroenterol. 2005;42(2):83-8.

11. Trotter JF, Wachs M, Everson GT, Kam I. Adult-to-adult transplantation of the right hepatic lobe from a living donor. N Engl J Med. 2002;346(14):1074-82.

12. Lo CM. Complications and long-term outcomes of living liver donors: a survey of 1508 cases in five Asian centers. Transplantation. 2003;75(Suppl):S12-5

13. Fisher RA, Cotterell AH, Maluf DG, Stravitz RT, Ashworth A Nakatsuka $\mathrm{M}$, et al. Adult living donor versus deceased donor live transplantation: a 10-year prospective single center experience. Ann Hepatol. 2009;8(4)298-307.

14. Gruttadauria S, di Francesco F, Vizzini GB, Luca A, Spada M, Cintorino D, et al. Early graft dysfunction following adult-to-adult living-related liver transplantation: predictive factors and outcomes. World $J$ Gastroenterol. 2009;15(36):4556-60.

15. Associação Brasileira de Transplante de Órgãos. Transplantes [Internet] Disponível em: http://www.abto.org.br. Acesso em: 21 maio 2012.

16. Ikegami T, Shimada M, Imura S, Arakawa Y, Nii A, Morine Y, et al. Current concept of small-for-size grafts in living donor liver transplantation. Surg Today. 2008;38(11):971-82

17. Marcos A. Right lobe living donor liver transplantation: a review. Liver Transpl. 2000;6(1):3-20.

18. Elola-Olaso AM, Gonzalez EM, Diaz JC, Garcia García I, Segurola CL, Usera MA, et al. Short- and long-term outcomes after living donor liver transplantation. Transplant Proc. 2005;37(9):3884-6.

19. Uchida $Y$, Kasahara M, Egawa H, Takada Y, Ogawa K, Ogura $Y$, et al. Long-term outcome of adult-to-adult living donor liver transplantation for post-Kasai biliary atresia. Am J Transplant. 2006:6(10):2443-8.

20. Jeon GS, Won JH, Wang HJ, Kim BW, Lee BM. Endovascular treatment of acute arterial complications after living-donor liver transplantation. Clin Radiol. 2008;63(10):1099-105.

21. Lo CM, Fan ST, Liu CL, Yong BH, Wong Y, Lau GK, et al. Lessons learned from one hundred right lobe living donor liver transplants. Ann Surg. 2004:240(1):151-8.
22. Londoño MC, Cárdenas A, Guevara M, Quintó L, de Las Heras D, Navasa M, et al. MELD score and serum sodium in the prediction of survival of patients with cirrhosis awaiting liver transplantation. Gut. 2007:56(9):1283-90.

23. Llach J, Ginès $P$, Arroyo $V$, Rimola A, Titó L, Badalamenti $S$, et al. Prognostic value of arterial pressure, endogenous vasoactive systems, and renal function in cirrhotic patients admitted to the hospital for the treatment of ascites. Gastroenterology. 1988;94(2):482-7.

24. Dawwas MF, Lewsey JD, Neuberger JM, Gimson AE. The impact of serum sodium concentration on mortality after liver transplantation: a cohort multicenter study. Liver Transpl. 2007;13(8):1115-24.

25. Weismüller TJ, Negm A, Becker T, Barg-Hock H, Klempnauer J, Manns MP, et al. The introduction of MELD-based organ allocation impacts 3-month survival after liver transplantation by influencing pretransplant patient characteristics. Transpl Int. 2009:22(10):970-8.

26. Biggins SW, Kim WR, Terrault NA, Saab S, Balan V, Schiano T, et al. Evidence-based incorporation of serum sodium concentration into MELD. Gastroenterology. 2006;130(6):1652-60.

27. Ruf AE, Kremers WK, Chavez LL, Descalzi VI, Podesta LG, Villamil FG Addition of serum sodium into the MELD score predicts waiting list mortality better than MELD alone. Liver Transpl. 2005;11(3):336-43.

28. Sirivatanauksorn $Y$, Taweerutchana V, Limsrichamrern S, Kositamongkol P, Mahawithitwong P, Asavakarn S, et al. Recipient and perioperative risk factors associated with liver transplant graft outcomes. Transplant Proc. 2012;44(2):505-8.

29. Moini M, Hoseini-Asl MK, Taghavi SA, Sagheb MM, Nikeghbalian S, Salahi $\mathrm{H}$, et al. Hyponatremia a valuable predictor of early mortality in patients with cirrhosis listed for liver transplantation. Clin Transplant. 2011;25(4):638-45.

30. Cywinski JB, Mascha E, Miller C, Eghtesad B, Nakagawa S, Vincent JP, et al. Association between donor-recipient serum sodium differences and orthotopic liver transplant graft function. Liver Transpl. 2008:14(1):59-65

31. Cywinski JB Mascha EJ, You J, Sessler DI, Kapural L, Argalious M, et al. Pre-transplant MELD and sodium MELD scores are poor predictors of graft failure and mortality after liver transplantation. Hepatol Int. 2011;5(3):841-9.

32. SelcukH,UrucI,Temel MA,Ocal S, Huddam B, Korkmaz M, etal.Factors prognostic of survival in patients awaiting liver transplantation for end-stage liver disease. Dig Dis Sci. 2007;52(11):3217-23.

\section{Endereço para correspondência}

Jaques Waisberg - Rua das Figueiras, 550, apto. 134 - Bairro Jardim CEP. 09080-300 - Santo André (SP), Brasil -

E-mail: jaqueswaisberg@uol.com.br

Fonte de financiamento: Sofia Abdalla recebeu Bolsa PIBIC - CNPq

Conflito de interesse: nada a declarar. 